\title{
Subclinical diabetic polyneuropathy: early detection of involvement of different nerve fibre
}

\author{
types
}

\author{
P H Hendriksen, P L Oey, G H Wieneke, B Bravenboer, A C van Huffelen
}

\begin{abstract}
Nerve conduction studies, tests of autonomic function and terminal nerve branches, and soleus muscle $H$ reflexes were applied to 60 patients with insulin dependent diabetes mellitus who had no clinical symptoms but abnormal vibratory or temperature perception thresholds indicating subclinical neuropathy. In most patients neurophysiological examination yielded a broad spectrum of neural dysfunction. The perception threshold for cold stimuli was sometimes selectively impaired and abnormal pupillometry results were common, suggesting that small fibres are vulnerable in the early stage of diabetic neuropathy. The arms were less frequently and less severely affected than the legs, an effect that may be related to nerve length. The neurophysiological test results did not change in 30 patients followed up for one year.
\end{abstract}

$(\Im$ Neurol Neurosurg Psychiatry 1993;56:509-514)

Diabetic neuropathies include a variety of distinct disorders affecting individual nerves or nerve roots, but more commonly the effects are seen in different nerve types and at multiple sites. The neuropathy is generally assessed with electrophysiological tests. Most of the commonly used methods for the detection of diabetic neuropathy, however, reflect only the loss of large fibres. ${ }^{1}$ Because unmyelinated fibre loss precedes abnormalities of large function, ${ }^{2}$ and because the extent of small fibre loss in most cases of asymptomatic polyneuropathy is not known, ${ }^{3}$ simultaneous assessment of different neurological functions mediated by different nerve fibre types might help to detect nerve involvement related to fibre type. Several classes of motor, sensory, and autonomic fibres must be considered. Dyck et al have shown that there are strong correlations between clinical abnormalities and neurophysiological indices in diabetic neuropathy, and they found a highly significant association between sural sensory nerve action potential amplitude and neuropathic symptoms. ${ }^{4}$ Sundkvist and Young et al studying asymptomatic patients with insulin dependent diabetes mellitus, found only a weak relation between peripheral somatic and autonomic abnormalities. Conflicting opinions exist on whether large myelinated (peripheral somatic), small myelinated, and unmyelinated (autonomic) nerve fibres are damaged in parallel by diabetes.

To evaluate nerve dysfunction related to fibre type and to compare the results of autonomic, motor end plate, sensory, and motor nerve function tests in a well defined group of 60 insulin dependent diabetic patients without symptoms of polyneuropathy, we performed $\mathrm{H}$ reflex of the soleus muscle, single fibre electromyography of the anterior tibial muscle, and pupillometry in addition to the established methods for the quantification of peripheral nerve dysfunction. ${ }^{7}$

To study the natural course of subclinical diabetic polyneuropathy, we followed up 30 diabetic patients for 12 months. Neurophysiological tests included psychophysical testing and pupillometry (reflecting small nerve fibre function), nerve conduction examination (reflecting large nerve fibre function), and single fibre electromyography (reflecting neuromuscular junction transmission function).

\section{Subjects and methods}

PATIENT SELECTION

Sixty patients, (37 men) with type I (insulin dependent) diabetes mellitus participated in this study. The mean (SD) age was 47 (12) years, range 20-71 years; the known duration of illness was 24 (10) years, range 4-50 years, and mean glycosylated haemoglobin $\mathrm{A}_{1}\left(\mathrm{HbA}_{1}\right)$ was $9 \cdot 3(2 \cdot 4) \%$. To study progress of polyneuropathy, 30 of these patients (22 men) were selected at random (mean age 47 (11) years, range 31-71 years; mean duration of illness 25 (11) years, range 6-50 years). The 30 other patients participated in a drug trial. Detailed information was present for all patients relating to duration of illness since diagnosis, concomitant drug therapy, and measures of diabetic control at onset. The patients were selected on the basis of the presence of a subclinical form of polyneuropathy according to the criteria of Dyck. ${ }^{8}$ They had no evidence of clinical neuropathy when evaluated with the neuropathy symptom score (NSS) and neurological symptom profile (NSP) ${ }^{4}$ but all had an abnormal vibratory perception threshold or an abnormal thermal discrimination threshold as a sign of polyneuropathy.

\section{EXAMINATIONS}

Clinical examination-Before the patients entered the study they were physically examined. They were admitted only if no abnormalities of sensation and muscle weakness were present on neurological examination or 
when laboratory data, including biochemical and haematological variables as well as urine analysis and electrocardiography, were normal. During the experimental period the metabolic state of all patients was controlled every four months. Concentrations of $\mathrm{HbA}_{1}$, serum glucose, total bilirubin, $\gamma$ glutamyltransferase, aspartate aminotransferase (SGOT), alanine amino transferase (SGPT), and lactate dehydrogenase did not change significantly during the twelve month study period (Wilcoxon signed rank test, two tailed).

Vibration perception threshold was measured at the dorsum of the second metacarpal of the right hand with an electromagnetic vibrameter (Somedic AB Vibrameter type III). The vibration threshold was determined by the method of limits. The stimulus strength was increased gradually from zero to the point where sensation was first perceived. The stimulus was then decreased to the point where the sensation first disappeared. This procedure was repeated, and the threshold was calculated from the average of the perception and disappearance thresholds. The results were compared with reference values. ${ }^{9}$

Thermal discrimination threshold was measured at the carpal site of the right forearm (Medelec Triple-T, Old Woking, Surrey). Heat threshold and cold threshold values were determined with a microcomputer controlled system and the two alternative forced choice method of psychophysical analysis. Results more than $2.5 \mathrm{SD}$ above the age matched mean value for normal individuals were considered abnormal. ${ }^{10}$

Nerve conduction studies of the left sural sensory nerve, the left posterior tibial motor nerve and the right motor and sensory ulnar nerve were performed with standard surface stimulating and recording techniques (Viking apparatus, Nicolet, Madison, Wisconsin). Results were considered abnormal if they deviated from the normal mean by more than $2.5 \mathrm{SD}$, on the basis of data published by Oh. ${ }^{11}$ To minimise the effects of temperature fluctuation the limbs were warmed in water baths at $34^{\circ} \mathrm{C}$ for 30 minutes before the test and kept at this temperature with an infrared heat lamp during the examination. The Hoffmann $(\mathrm{H})$ reflex of the soleus muscle was evoked by transcutaneous bipolar electrical stimulation of the tibial nerve in the popliteal fossa. ${ }^{12}$ For normal data, Hoffmann reflex latencies (H-M interval) in relation to age and height as published by Visser et $a l^{13}$ were used.

Single fibre electromyography (SFEMG) of the anterior tibial muscle was recorded (Dantec Counterpoint apparatus, Skovlunde, Denmark) by inserting the electrode into weakly contracting muscle as described by Stålberg et al. ${ }^{14}$ Mean neuromuscular jitter was expressed as the mean consecutive difference for 20 pairs of potentials and was considered abnormal if the value exceeded $60 \cdot 2$ $\mu \mathrm{s}$. The mean fibre density was calculated for 20 sampled recording potentials and was considered abnormal if it exceeded $2 \cdot 28$.
Autonomic function testing - Static and dynamic pupillometry were performed in darkness. For static pupillometry the pupil diameter was measured after 2 and 4 minutes of dark adaptation by infrared photography. ${ }^{15}$ The mean pupil diameter was determined from the two photographs in relation to the horizontal iris diameter and expressed as percentage of pupil diameter (PD\%). For dynamic pupillometry the infrared light reflex technique (IRIS) was used. ${ }^{16}$ With infrared light emitting diodes and sensors mounted on a frame in front of both eyes, variations in pupil size were recorded after a light stimulus was placed in front of the right eye. The block shaped stimulus, which was given every 5 seconds, had an intensity of 3.7 log Troland (Troland $=$ retinal illuminance) and a duration of 1.2 seconds. Measurement of the latency between the onset of the stimulus and the start of the constriction started from the first deflection in the differentiated signal. ${ }^{17}$ The latency of pupillary constriction (LC) was determined from at least 10 artefact free responses for both eyes. Values more than 2.5 standard deviations beyond means for control subjects of the same age, as published by Smith and Dewhurst ${ }^{18}$ for PD\% and Lanting et $a l,{ }^{19}$ for LC were regarded as abnormal.

\section{PROCEDURE}

Sixty patients were examined electrophysiologically; 30 of these were selected at random for longitudinal monitoring. The examinations took place after 4,8 , and 12 months. All neurophysiological evaluations consisted of determining vibration and temperature thresholds, motor and sensory conduction studies, $\mathrm{H}$ reflex measurement, and static and dynamic pupillometry. During the first examination, and after 12 months, SFEMG of the anterior tibial muscle was performed as well.

Before each neurophysiological examination the patients underwent a physical examination and laboratory data (haematological and biochemical data, blood glucose profile, and ECG) were collected to ensure that the patient's condition had not changed. All examinations were done by the same investigator.

\section{ANALYSIS}

Twenty three variables were used for the statistical analyses (see table 4). For perception threshold we used vibration threshold (VT), heat discrimination threshold (HT), and cold discrimination threshold (CT); for motor ulnar and tibial nerve, distal motor latency (DML) (distance of distal stimulation to the active recording electrode, $8 \mathrm{~cm}$ for both the right ulnar and left tibial nerve), amplitude of the compound muscle action potential from distal stimulation (AMP), ratio of amplitude of compound muscle action potential from proximal and distal sites (AR), and motor nerve conduction velocity (MNCV); for sensory ulnar and sural nerve, sensory nerve conduction velocity (SNCV); (distance of distal stimulation to the active electrode, approximately $14 \mathrm{~cm}$ for both the right ulnar and left 
Table 1 Results of clinical neurophysiological examinations

\begin{tabular}{llc}
\hline Test & No with test response & Mean (SD) \\
\hline Tibial nerve (MNCV) & 53 & $33 \cdot 5(7 \cdot 9) \mathrm{m} / \mathrm{s}$ \\
H reflex (soleus muscle) & 44 & $32 \cdot 2(15 \cdot 3) \mathrm{ms}$ \\
Pupil diameter percentaget & 53 & $44 \cdot 0(8 \cdot 9) \%$ \\
Latency of pupil constriction† & 53 & $244 \cdot 1(33) \mathrm{ms}$ \\
Sural nerve (SNCV) & 45 & $35.9(10 \cdot 1) \mathrm{m} / \mathrm{s}$ \\
SFEMG: & & \\
$\quad$ Mean jitter & 57 & $71 \cdot 1(16 \cdot 2) \mu \mathrm{s}$ \\
$\quad$ Fibre densityt & 57 & $3.01(1.8)$ \\
Ulnar nerve: & & \\
SNCV & 56 & $42.5(15 \cdot 1) \mathrm{m} / \mathrm{s}$ \\
MNCV & 60 & $53.4(5.6) \mathrm{m} / \mathrm{s}$ \\
\hline
\end{tabular}

MNCV = motor nerve conduction velocity; SNCV = sensory nerve conduction velocity

* Latency $H$ reflex minus latency $M$ response; value depends on age and height.

tValue depends on age. sural nerve) and amplitude of the sensory nerve action potential (AMP); for soleus muscle, $\mathrm{H}-\mathrm{M}$ interval $(\mathrm{H}-\mathrm{M})$ and $\mathrm{H}-\mathrm{M}$ ratio amplitude from $\mathrm{H}$ reflex; from SFEMG, fibre density (FD) and mean of mean consecutive difference (MJ); and for pupillometry, pupil diameter as a percentage of iris diameter (PD\%) and constriction latency of the pupil to light (LC).

Although the selection criteria used implied that the 60 patients had no clinical symptoms of polyneuropathy, the presence of neurophysiological abnormalities had to be assessed. Therefore we compared measurements on 18 variables with normal values reported in the literature. Measurements more than $2.5 \mathrm{SD}$ from the mean were considered abnormal; when a response could not be elicited the result was interpreted as abnormal.

Correlations among the different tests were examined. When no response had been

Table 2 Percentage of patients with abnormal results (values $>2 \cdot 5 S D$ from mean)

\begin{tabular}{|c|c|c|c|c|}
\hline & \multicolumn{2}{|c|}{ No of patients } & \multirow[b]{2}{*}{ Limit value } & \multirow[b]{2}{*}{$\%$ Abnormal } \\
\hline & Total & $\begin{array}{l}\text { Response not } \\
\text { obtained }\end{array}$ & & \\
\hline $\begin{array}{l}\text { Perception threshold: } \\
\text { Cold threshold (CT) } \\
\text { Heat threshold (HT) } \\
\text { Vibration threshold (VT) }\end{array}$ & $\begin{array}{l}60 \\
60 \\
60\end{array}$ & & $\begin{array}{l}<0 \cdot 28^{\circ} \mathrm{C} \\
<0 \cdot 32^{\circ} \mathrm{C} \\
<1 \cdot 00^{\star}\end{array}$ & $\begin{array}{l}98 \\
58 \\
33\end{array}$ \\
\hline $\begin{array}{l}\text { Pupillometry: } \\
\text { Dynamic (LC) } \\
\text { Static (PD\%) }\end{array}$ & $\begin{array}{l}53 \\
53\end{array}$ & & $\begin{array}{l}<225 \mathrm{~ms} \\
>42 \%^{\star}\end{array}$ & $\begin{array}{l}80 \\
76\end{array}$ \\
\hline $\begin{array}{l}\text { H reflex soleus muscle: } \\
\text { H-M interval }\end{array}$ & 60 & 16 & $<31.8 \mathrm{~ms}^{\star}$ & 66 \\
\hline $\begin{array}{l}\text { SFEMG: } \\
\text { Mean jitter } \\
\text { Fibre density }\end{array}$ & $\begin{array}{l}57 \\
57\end{array}$ & & $\begin{array}{l}<62.5 \mu \mathrm{s} \\
<2 \cdot 28\end{array}$ & $\begin{array}{l}58 \\
48\end{array}$ \\
\hline $\begin{array}{l}\text { Peripheral nerve conduction } \\
\text { Tibial nerve } \\
\text { MNCV } \\
\text { AMP } \\
\text { DML }\end{array}$ & $\begin{array}{l}60 \\
60 \\
60\end{array}$ & $\begin{array}{l}7 \\
7 \\
7\end{array}$ & $\begin{array}{l}>34.1 \mathrm{~m} / \mathrm{s} \\
>4.5 \mathrm{mV} \\
<5.4 \mathrm{~ms}\end{array}$ & $\begin{array}{l}53 \\
32 \\
12\end{array}$ \\
\hline $\begin{array}{l}\text { Sural nerve } \\
\text { SNCV } \\
\text { AMP }\end{array}$ & $\begin{array}{l}60 \\
60\end{array}$ & $\begin{array}{l}20 \\
20\end{array}$ & $\begin{array}{l}>37.6 \mathrm{~m} / \mathrm{s} \\
>4.5 \mu \mathrm{V}\end{array}$ & $\begin{array}{l}50 \\
48\end{array}$ \\
\hline $\begin{array}{l}\text { Ulnar nerve (sensory) } \\
\text { SNCV } \\
\text { AMP }\end{array}$ & $\begin{array}{l}60 \\
60\end{array}$ & $\begin{array}{l}4 \\
4\end{array}$ & $\begin{array}{l}>41.9 \mathrm{~m} / \mathrm{s} \\
>4.5 \mu \mathrm{V}\end{array}$ & $\begin{array}{l}27 \\
24\end{array}$ \\
\hline $\begin{array}{l}\text { Ulnar nerve (motor) } \\
\text { MNCV } \\
\text { AMP } \\
\text { DML }\end{array}$ & $\begin{array}{l}60 \\
60 \\
60\end{array}$ & & $\begin{array}{l}>45.4 \mathrm{~m} / \mathrm{s} \\
>7.2 \mathrm{mV} \\
<4.5 \mathrm{~ms}\end{array}$ & $\begin{array}{l}20 \\
10 \\
10\end{array}$ \\
\hline
\end{tabular}

ॠValue depends on age or height, or both.

DML = distal motor latency; AMP = amplitude of distal compound muscle action potential or sensory nerve action potential; $M N C V=$ motor nerve conduction velocity; $S N C V=$ sensory nerve conduction velocity; $L C=$ latency of pupil constriction to light; $P D \%=$ pupil diameter as percentage of iris diameter. obtained, the result was placed at the abnormal end of the distribution for that test. Nonparametric correlation analysis was performed with Spearman's rank correlation.

Thirty patients were assessed longitudinally to monitor functional changes. A Friedmann two way analysis of variance was used to evaluate possible changes in the values of each variable. To assess the effect of examinations in which abnormality was too large to elicit a response, the analysis was restricted to the repeatedly measurable data. In this analysis data from patients in whom the sural nerve conduction velocity or $\mathrm{H}-\mathrm{M}$ interval of the $\mathrm{H}$ reflex of the soleus muscle could not be elicited during the first examination were excluded. The variation in repeated examinations was calculated by expressing the change in these results from baseline as a percentage, and the absolute changes in the three follow up examinations were averaged.

\section{Results}

The mean (SD) values of the baseline data are shown in table 1 . The percentage of patients with abnormal test results (values more than $2.5 \mathrm{SD}$ from the mean) are shown in table 2.

The psychophysical examinations (VT, HT, CT) were used as selection criteria, yielding an overall abnormality of $100 \%$, and were therefore not included in the analyses. However, the thermal threshold was selectively impaired in some patients, suggesting that small fibres are more prone to damage in diabetic neuropathy. Static and dynamic pupillometry, which are also considered as tests to determine the function of small nerve fibres, were often abnormal as well. The nerve conduction studies did not follow a definite pattern of involvement. Clustering of tests with unobtainable responses or tests with pronounced abnormalities were not found. For example, only four of the 30 patients in whom a suralis response could not be elicited had an unrecordable $\mathrm{H}$ reflex. Generally, the $\mathrm{H}-\mathrm{M}$ interval of the Hoffmann reflex was most likely to be affected and the ulnar nerve distal motor latency was the least likely to be affected. Nerve conduction abnormalities were most pronounced in motor nerves of the leg, (Tib MNCV), followed, in order of severity, by sensory nerves of the leg (sural SNCV), sensory nerves of the arm (ulnar SNCV), and motor nerves of the arm (ulnar MNCV). It thus seems that the thin myelinated and unmyelinated autonomic nerves were most often affected, followed by the fibres conducting the $\mathrm{H}$ reflex.

Spearman's rank correlation coefficients between variables are presented in table 3 . In general, the different conduction systems were poorly correlated. However, the correlations between the conduction function of the relatively short nerves in the arms with those of the longer nerves in the legs were moderate $(0 \cdot 61-0.71)$, suggesting that there was still no difference related to nerve length at this stage of polyneuropathy. 
Table 3 Correlations between different electrophysiological variables on nerve function in 60 patients with insulin dependent diabetes

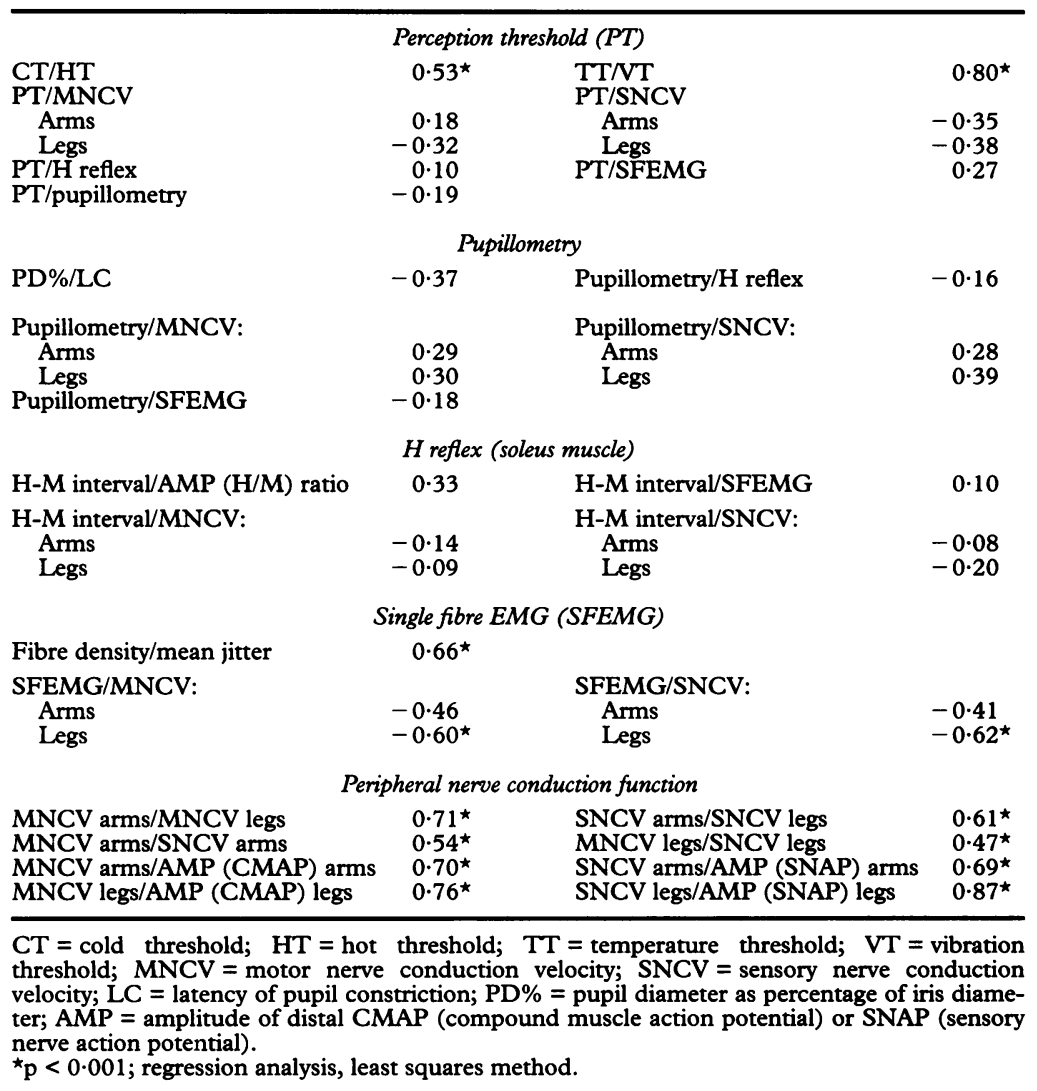

Table 4 Comparison of electrophysiological variables in longitudinal assessment of nervt function

\begin{tabular}{|c|c|c|c|c|}
\hline & $\begin{array}{l}\text { No with } \\
\text { pain } \\
\text { measurements }\end{array}$ & $\begin{array}{l}\text { Mean }(S D) \text { at } \\
\text { start }(n=30)\end{array}$ & $\begin{array}{l}\text { Mean } \\
\text { correlation } \\
\text { coefficient }\end{array}$ & $\begin{array}{l}\text { Mean } \\
\% \text { change } \\
\text { in paired } \\
\text { measurements }\end{array}$ \\
\hline $\begin{array}{l}\text { Perception threshold: } \\
\text { Cold threshold (CT) } \\
\text { Heat threshold (HT) } \\
\text { Vibration (VT) }\end{array}$ & $\begin{array}{l}30 \\
30 \\
30\end{array}$ & $\begin{array}{l}0.68(0.37) \\
0.73(0.41) \\
2.19(1.21)\end{array}$ & $\begin{array}{l}0 \cdot 61 \\
0 \cdot 68^{\star} \\
0 \cdot 67\end{array}$ & $\begin{array}{l}21 \cdot 0 \\
16 \cdot 8 \\
14 \cdot 4\end{array}$ \\
\hline $\begin{array}{l}\text { Pupillometry: } \\
\text { Dynamic (latency) } \\
\text { Static (PD\%) }\end{array}$ & $\begin{array}{l}29 \\
28\end{array}$ & $\begin{array}{r}245 \cdot 1(27 \cdot 0) \\
47 \cdot 4(6 \cdot 59)\end{array}$ & $\begin{array}{l}0.64^{\star \star} \\
0.86^{\star \star}\end{array}$ & $\begin{array}{l}2 \cdot 5 \\
2 \cdot 6\end{array}$ \\
\hline $\begin{array}{l}\text { H reflex (soleus muscle): } \\
\text { H-M interval } \\
\text { Amplitude ratio }\end{array}$ & $\begin{array}{l}23 \\
23\end{array}$ & $\begin{array}{c}29.90(3.34) \\
0.1(0.06)\end{array}$ & $\begin{array}{l}0.64 \\
0.83^{\star \star}\end{array}$ & $\begin{array}{r}4 \cdot 1 \\
18 \cdot 5\end{array}$ \\
\hline $\begin{array}{l}\text { SFEMG: } \\
\text { Fiber density } \\
\text { Mean jitter }\end{array}$ & $\begin{array}{l}29 \\
29\end{array}$ & $\begin{array}{r}2 \cdot 21(0.38) \\
66 \cdot 14(13.9)\end{array}$ & $\begin{array}{l}0.78^{\star \star} \\
0.60^{\star \star}\end{array}$ & $\begin{array}{l}5 \cdot 0 \\
2 \cdot 6\end{array}$ \\
\hline $\begin{array}{l}\text { Peripheral nerve conduct } \\
\text { Tibial nerve: } \\
\text { DML } \\
\text { AMP } \\
\text { AR } \\
\text { MNCV }\end{array}$ & $\begin{array}{l}\text { In function: } \\
26 \\
26 \\
26 \\
26\end{array}$ & $\begin{array}{r}4 \cdot 19(0.63) \\
6 \cdot 11(2 \cdot 01) \\
0.61(0.20) \\
37.98(4 \cdot 83)\end{array}$ & $\begin{array}{l}0 \cdot 75^{\star \star} \\
0 \cdot 89^{\star \star} \\
0 \cdot 75^{\star \star} \\
0 \cdot 92^{\star \star}\end{array}$ & $\begin{array}{l}2 \cdot 8 \\
7 \cdot 7 \\
1 \cdot 7 \\
1 \cdot 5\end{array}$ \\
\hline $\begin{array}{l}\text { Sural nerve: } \\
\text { LAT } \\
\text { AMP } \\
\text { SNCV }\end{array}$ & $\begin{array}{l}19 \\
19 \\
19\end{array}$ & $\begin{array}{r}2 \cdot 09(0 \cdot 76) \\
3 \cdot 89(2 \cdot 12) \\
36 \cdot 45(4 \cdot 92)\end{array}$ & $\begin{array}{l}0 \cdot 66^{\star \star} \\
0 \cdot 80^{\star \star} \\
0 \cdot 77^{\star \star}\end{array}$ & $\begin{array}{l}9 \cdot 0 \\
5 \cdot 3 \\
2 \cdot 3\end{array}$ \\
\hline $\begin{array}{l}\text { Ulnar nerve (motor): } \\
\text { DML } \\
\text { AMP } \\
\text { AR } \\
\text { MNCV }\end{array}$ & $\begin{array}{l}30 \\
30 \\
30 \\
30\end{array}$ & $\begin{array}{r}3.38(0.60) \\
8.74(1.97) \\
0.89(0.14) \\
53.47(5.63)\end{array}$ & $\begin{array}{l}0 \cdot 88^{\star \star} \\
0 \cdot 90^{\star} \\
0 \cdot 51^{\star} \\
0 \cdot 78^{\star \star}\end{array}$ & $\begin{array}{l}3 \cdot 0 \\
4 \cdot 9 \\
1 \cdot 8 \\
1 \cdot 1\end{array}$ \\
\hline $\begin{array}{l}\text { Ulnar nerve (sensory): } \\
\text { LAT } \\
\text { AMP } \\
\text { SNCV }\end{array}$ & $\begin{array}{l}27 \\
27 \\
27\end{array}$ & $\begin{array}{r}2.96(1.06) \\
5.54(2.00) \\
43.73(3.48)\end{array}$ & $\begin{array}{l}0.47^{\star} \\
0 \cdot 73^{\star \star} \\
0 \cdot 81^{\star \star}\end{array}$ & $\begin{array}{r}10 \cdot 9 \\
6 \cdot 2 \\
2 \cdot 7\end{array}$ \\
\hline
\end{tabular}

${ }^{\star} \mathrm{p}<0.01 ;{ }^{\star \star} \mathrm{p}<0.001$.

$\mathrm{DML}=$ distal motor latency; $\mathrm{AMP}=$ amplitude of distal compound muscle action potential or sensory nerve action potential; $A R=$ amplitude ratio form proximal and distal sites; $M N C V=$ motor nerve conduction velocity; LAT = sensory latency; $\mathrm{SNCV}=$ sensory nerve conduction motor ne
velocity.
The results of the changes in the variables in the longitudinal assessment in comparison with the starting results are shown in table 4. Although the values showed fluctuations over the period, no general trends were evident. When the changes for each variable were analysed (Friedmann two way analysis of variance, $p>0 \cdot 10$ ), none of the electrophysiological variables changed significantly over the test period. The fluctuations could presumably be attributed to measurement errors. Reproducibility was tested in two ways. Firstly, for each variable the correlation of the repeated examinations was determined. The averaged correlation coefficients indicate the variation in repeated examinations. Secondly, for all variables the mean percentage of change from baseline value during longitudinal assessment was calculated (table 4). For the temperature and vibration threshold tests, the variation seemed to be high, whereas it was lowest for nerve conduction velocity tests in the arms. On repeated measurement the variation ranged from $1 \cdot 1 \%$ (ulnar MNCV) to $21 \%$ (CT). Overall, the variation was lower in the arms than in the legs. The tests on neuromuscular transmission and thin myelinated and unmyelinated (autonomic) nerve fibres, SFEMG, and pupillometry showed variations of about $2.5 \%(\mathrm{MJ}, \mathrm{PD} \%$, LC).

Comparison of the amplitudes of the proxi$\mathrm{mal}$ and distal ulnar compound muscle action potential showed a decrease in amplitude of $11 \%$ (table 4: amplitude ratio (AR) 0.89 $( \pm 0 \cdot 14))$. However, a relatively high correlation was found between distal amplitude and conduction velocity (table 3: 0.70 for the ulnar nerve). This implies that there were no indications of segmental demyelination manifested by a decrease in amplitude ratio of more than $20 \%{ }^{20}$ in this population.

\section{Discussion}

Subclinical diabetic neuropathy was assessed by evaluating psychophysical deficits, abnormalities of neuromuscular transmission, sensory and motor nerve conduction function, and quantitative autonomic function in the absence of clinical symptoms. Quantitation of vibratory sensation and determination of thermal discrimination thresholds were used to select the study population. These tests examined large and small fibre function separately. ${ }^{21}$ The results depend on the local intergrity of nerve endings as well as on nerve conduction. $^{22}$ This study is not unique in finding a discrepancy between the lack of symptoms and the results of the measurements of psychophysical functions. ${ }^{23}$ Thermal sensitivity was sometimes selectively affected, suggesting that in the subclinical form of diabetic neuropathy the small fibres are more vulnerable. Ali et al reported similar results. ${ }^{24}$

It was our aim to evaluate the diagnosis of subclinical polyneuropathy and the extent of nerve involvement at this stage of illness by examining the function of all types of nerve fibres. Many tests have been used to detect 
and characterise diabetic polyneuropathy, but the value of simultaneous and extensive testing for detecting and monitoring early nerve dysfunction in diabetic patients has been inadequately assessed. Dyck published an overview of the literature and devices to detect and assess diabetic polyneuropathy. ${ }^{8}$ The present study is a clinical approach in line with these devices. Patients with a subclinical form of neuropathy were selected as we expected that histopathological changes would not be advanced. Only in this early stage of illness would extensive neurophysiological examination help to assess the possible involvement of selective nerve fibres.

The technique most commonly used is the measurement of motor and sensory nerve conduction velocity. Conduction velocity is a function of a number of physiological properties. Fibre size, myelination, nodal and internodal length, and external and internal axonal resistance have a role in the speed of conduction. Nerve conduction testing uses supramaximal stimuli, thereby recruiting non-selectively all available fibres. Only the state of the largest, most rapidly conducting, myelinated fibres is examined.

In an attempt to examine all fibre types selectively, pupillometry, $H$ reflex of the soleus muscle, and single fibre EMG were performed in addition to the methods most commonly used. In our patients the pupil diameter in relation to the iris diameter (PD\%) and the latency of constriction of the pupil to light were often abnormal. These findings indicate impairment of the reflex arcs involving small myelinated and unmyelinated parasympathetic nerves to the eye and sympathetic nerves to the iris. ${ }^{19}$ The weak correlation between autonomic pupillary function and peripheral nerve conduction function tests suggests a lack of association between autonomic neuropathy and peripheral nerve fibre dysfunction. With the $\mathrm{H}$ reflex ( $\mathrm{H}-\mathrm{M}$ interval) it is possible to determine motor and sensory fibre function simultaneously. This test is a sensitive means of detecting proximal nerve trunk dysfunction and is valuable because it can reveal abnormalities before the neuropathy becomes clinically manifest. ${ }^{25}$ Our data confirm this assumption, as two thirds of the patients showed an increase in the $\mathrm{H}-\mathrm{M}$ interval. SFEMG was performed as part of the electrophysiological examination to assess terminal axonal function and measure neuromuscular transmission. ${ }^{26}$ This is a relatively new test in clinical use and showed abnormal findings in $48 \%$ of the patients.

Most of our diabetic patients had, despite the absence of clinical symptoms, signs of peripheral nerve dysfunction, as well as evidence of impairment of the reflex arcs involving parasympathetic nerves to the eye and sympathetic nerves to the iris. Nerve conduction abnormalities were widespread, involving proximal and distal parts of the nerve trunks. The relative involvement of large and small fibres was not uniform.

In longitudinal studies, the reproducibility of the tests is of major importance. However, before interpreting neurophysiological data on serial determinations and drawing conclusions about examination variation, two associated problems should be addressed. The first problem is the lack of knowledge about the natural progress of diabetic polyneuropathy. In the present study, where all nerve fibre types were selectively examined, the results of the longitudinal clinical neurophysiological tests did not change throughout the examination period. No support was found for the concept of a progression of neuropathic damage, or from small fibre dysfunction initially to loss of function in large fibres later on.

The second problem focuses on the observation that measurements of nerve function should be objective, sensitive, specific, and reproducible and therefore useful in a follow up evaluation of diabetic neuropathy. In this study the psychophysical tests showed considerable variation at follow up examination: on repeated testing, patients with borderline normal perception thresholds could become abnormal, and vice versa. High examination variations for vibratory perception thresholds and thermal discrimination thresholds have been reported previously. ${ }^{3}$ This variability may be partly due to fluctuations in room temperature and in the patient's attention. Of the nerve conduction measurements, motor and sensory nerve conduction velocities and distal motor latencies were the most reproducible, with only $1 \cdot 1 \%$ to $4 \cdot 1 \%$ variation; amplitude had the lowest reproducibility $(4.9 \%$ to $7.7 \%$ variation). Although the nerve function of the legs seemed to show a greater magnitude of abnormality, in the longitudinal assessment the variation was greater than that of tests assessing the function of the arm nerves and seemed inversely proportional to the length of the tested nerve. Main sources of this variation might be the error in latency readings and distance measurements. ${ }^{27}$ It may be because of the relatively short length of the tested nerve segment that the $\mathrm{H}$ reflex $(\mathrm{H}-\mathrm{M}$ interval) showed considerable interexamination stability.

One of our objectives in this study was to assess which combination of clinical neurophysiological tests could be used for evaluating the diagnosis reliably and for the early detection of diabetic neuropathy. Reliability of the neurophysiological evaluation depends on the sensitivity and the selectivity of the tests to assess the function of different types of nerve fibre. The present data show the necessity of extensive clinical neurophysiological testing rather than the standard techniques to detect selective nerve fibre involvement in patients with a subclinical form of diabetic neuropathy. Because nerves are not affected to the same extent, even in the early stage of illness, we suggest the use of a combination of methods to examine all nerve fibres selectively, not restricting the examination to thick myelinated nerve fibres.

The choice of tests and their diagnostic use for detecting and monitoring nerve dysfunction is a matter of discussion as the results of each test and their reproducibility reflect an 
interaction between test sensitivity and biological expression. In this study the $\mathrm{H}$ reflex of the soleus seemed to be a sensitive and reproducible test. Other sensitive and reproducible tests were pupillometry and motor or sensory conduction velocity in tibial and sural nerves. These three tests were not correlated and thus provided information on different nerve systems. The nerve conduction function tests in nerves of the arms and the legs were highly correlated. Evaluation of motor and sensory nerve conduction function can therefore, be restricted to the most sensitive test.

The diagnostic yield and also the discomfort to the patient are important factors to consider when choosing a method. SFEMG (reflecting motor end plate function) may therefore not be useful for routine examination. Furthermore, SFEMG of tibial anterior muscle was highly correlated with motor nerve conduction velocity of the tibial nerve. We suggest that a combination of tests reflecting function of small nerve fibres as well as of thick and fast conducting myelinated nerves should be used for early and selective detection of diabetic polyneuropathy.

1 Pirart J. Diabetes mellitus and its degenerative complications: a prospective study of 4400 patients observed tions: a prospective study of 4400 patients observed
between 1947 and 1973 . Diabetes Care 1978;1:168-88, 252-63.

2 Guy RJC, Clark CA, Malcolm PN, Watkins PJ. Evaluation of thermal and vibration sensation in diabetic neuropathy. Diabetologia 1985;28:131-7.

3 Levy DM, Abraham RR, Abraham RM. Small- and largefiber involvement in early diabetic neuropathy: a study with the medial plantar response and sensory thresholds. Diabetes Care 1987;10:441-7.

4 Dyck PJ, Karnes JL, Daube J, O'Brien P, Service FJ. Clinical and neuropathological criteria for the diagnosis and staging of diabetic polyneuropathy Brain and staging of

5 Sundkvist G. Autonomic nervous function in asymptomatic diabetic patients with signs of peripheral neuropathy. Diabetes Care 1981;4:529-34.

6 Young RJ, Ewing DJ, Clarke BF. Nerve function and metabolic control in teenage diabetics. Diabetes 1983;32:142-7.

7 Masson EA, Veves A, Fernando D, Boulton AJM. Current perception thresholds: a new, quick, and reproducible method for the assessment of peripheral neuropathy in diabetes mellitus. Diabetologia 1989;32: 724-8.
8 Dyck PJ. Detection, characterisation, and staging of polyneuropathy: assessed in diabetes. Muscle Nerve polyneuropathy:

9 Goldberg JM, Lindblom U. Standardised methods of determining vibratory perception threshold for diagnosis and screening in neurological investigation. $f$ Neurol and screening in neurological investigat

10 Jamal GA, Weir AI, Hansen S, Ballantyne JP. An improved automated method for the measurement of thermal thresholds: two patients with peripheral neuropathy. F Neurol Neurosurg Psychiatry 1985;48:361-6.

$11 \mathrm{Oh}$ SJ. Clinical electromyography: nerve conduction studies. Baltimore; University Park Press, 1984:93-113.

12 Troni W, Cantello R, Rainero E. The use of the H-reflex in serial evaluation of nerve conduction velocity. Electroenceph Clin Neurophys 1983;55:82-90.

13 Visser SL, Zonneveldt A, De Rijke W. Normal Hoffmann reflex latencies (H-M interval) in relation to age and reflex latencies (H-M interval) in relation to age
body length. Clin Neurol Neurosurg 1983;85:85-91.

14 Stålberg E, Schiller HH, Schwartz MS. Safety factor in human motor end plates studies in vivo with SFEMG. $\mathcal{f}$ human motor end plates studies in vivo with

15 Smith SA, Smith SE. Evidence for a neuropathic aetiology in the small pupil of diabetes mellitus. $\mathcal{F}$ Ophthalmol 1983;67:89-93.

16 Reulen JPH, Marcus JT, van Gilst MJ. Stimulation and recording of dynamic pupillary reflex: the IRIS technique. Part 2. Med Biol Eng Comp 1988;26:27-32.

17 Lanting P, Bos JE, Aartsen J, Schuman L, ReichertThoen J, Heimans JJ. Assessment of pupillary light reflex latency and darkness adapted pupil size in control subjects and in diabetic patients with and without cardiovascular autonomic neuropathy. $F$ Neurol Neurosurg diovascular autonomic neurc
Psychiatry 1990;53:912-4.

18 Smith SA, Dewhurst R. A simple diagnostic test for pupillary abnormality in diabetic autonomic neuropathy. Diabetes Med 1985;3:38-41.

19 Lanting P, Heimans J, Reulen JPH, Nauta J, Van der Veen EA. Pupillary light reflex and quantitative sensory and motor neural function tests in diabetic patients. $f$ Neurol 1988;235:245-7.

20 Feasby TE, Brown WF, Gilbert J, Hayn AF. The pathological basis of conduction block in human neuropathies. I Neurol Neurosurg Psychiatry 1985;43: 239-44.

21 Dyck PJ, Karnes J, O'Brien PC, Zimmerman JR. Detection thresholds of cutaneous sensation in humans. In: Dyck PJ, Thomas PK, Lambert EH, Bunge R, eds. Peripheral neuropathy. Vol 1. Philadelphia; Saunders, Peripheral neuropat

22 Rendell MS, Katims J, Richter R. A comparison of nerve conduction velocities and current thresholds as correlates of clinical severity of diabetic sensory neuropathy f Neurol Neurosurg Psychiatry 1989;52:502-11.

23 Greene DA, Pfeifer MA. Diabetic neuropathy. In Olekfsky JM, ed. Contemporary issues in endocrinology and metabolism. Diabetes mellitus, management and complications. New York; Churchill Livingstone, 1985:223-54.

24 Ali Z, Carroll M, Robertson KP, Fowler CJ. The extent of small fibre sensory neuropathy in diabetics with plantar foot ulceration. F Neurol Neurosurg Psychiatry 1989; 52:94-8.

25 Bertelsmann FW, Heimans J, Van Rooy JCGM, Visser $\mathrm{SL}$. Comparison of Hoffmann reflex with quantitative $\mathrm{SL}$. Comparison of Hoffmann refiex with quantitative thy. Acta Neurol Scand 1986;74:121-7.

26 Stålberg E, Trontelj JV. Single fibre electromyography. Old Woking, Surrey: Mirvalle Press, 1979:1-244.

27 Daube JR. Electrophysiologic testing in diabetic neuropathy. In: Dyck PJ, Thomas PK, eds. Diabetic neuropathy. Vol 17. Philadelphia; Saunders, 1987:162-76. 